\title{
The Diagnosis and Treatment of Anxiety Disorders
}

\author{
Andreas Ströhle, Jochen Gensichen, Katharina Domschke
}

Department of Psychiatry and Psychotherapy, Campus Charité Mitte (CCM) Charité-Universitätsmedizin Berlin: Prof. Dr. med. Andreas Ströhle

Institute of General Practice, Faculty of Medicine, LudwigMaximilians-Universität München: Prof. Dr. med. Dipl.-Päd. Jochen Gensichen, MPH

Department of Psychiatry and Psychotherapy, University Hospital of Freiburg: Prof. Dr. Dr. med. Katharina Domschke

\section{Summary}

Background: Anxiety disorders are the most common type of mental illness in Europe, with a 12-month prevalence of $14 \%$ among persons aged 14 to 65 . Their onset is usually in adolescence or early adulthood. The affected patients often develop further mental or somatic illnesses (sequential comorbidity).

Methods: This review is based on pertinent publications retrieved by a selective search in PubMed.

Results: The group of anxiety disorders includes generalized anxiety disorder (GAD), phobic disorders, panic disorders, and two disorders that are often restricted to childhood-separation anxiety and selective mutism. A comprehensive differential diagnostic evaluation is essential, because anxiety can be a principal manifestation of other types of mental or somatic illness as well. Psychotherapy and treatment with psychoactive drugs are the therapeutic strategies of first choice. Of all types of psychotherapy, cognitive behavioral therapy has the best documented efficacy. Modern antidepressants are the drugs of first choice for the treatment of panic disorders, agoraphobia, social phobia, and GAS; pregabalin is a further drug of first choice for GAS.

Conclusion: In general, anxiety disorders can now be effectively treated. Patients should be informed of the therapeutic options and should be involved in treatment planning. Current research efforts are centered on individualized and therefore, it is hoped, even more effective treatment approaches than are available at present.

\section{Cite this as:}

Ströhle A, Gensichen J, Domschke K: The diagnosis and treatment of anxiety disorders. Dtsch Arztebl Int 2018; 115: 611-20. DOI: $10.3238 /$ arztebl.2018.0611

A nxiety is a a normal and necessary basic emotion without which individual survival would be impossible. Pathologically increased anxiety can arise not only in anxiety disorders per se, but also in most other types of mental illness. Anxiety can also be a warning signal of potential harm in somatic illnesses, such as myocardial infarction or hypoglycemia in a diabetic patient; it naturally requires an entirely different therapeutic approach in such situations. For any patient presenting with pathologically increased anxiety, a thorough psychiatric and somatic evaluation is needed so that an underlying pulmonary (e1), cardiovascular (e2), neurological (e3), or endocrine disease (e.g., of the thyroid gland) (e4) can be ruled out. Anxiety reactions as such are important indicators of a possible threat to homeostasis; anxiety is considered a disease requiring treatment when it arises in the absence of any threat, or in disproportionate relation to a threat, and keeps the affected individual from leading a normal life.

\section{Learning objectives}

After reading this article, the reader should

- know that anxiety disorders are common mental illnesses of early onset that elevate the risk of developing further mental illnesses;

- understand the clinical manifestations of anxiety disorders;

- be aware of the current treatments of first choice.

\section{Methods}

This review is based on pertinent publications retrieved by a selective search in PubMed.

\section{Anxiety disorders}

Anxiety is considered a disease requiring treatment when it arises in the absence of any threat, or in disproportionate relation to a threat, and keeps the affected individual from leading a normal life.

\section{Sex ratio}

Women are affected two to three times as commonly as men. 


\section{Epidemiology}

Anxiety disorders are the most common type of mental illness in the European Union, Switzerland, Iceland, and Norway (figures for the year 2010). With a 12-month prevalence of $14 \%$ and approximately 61.5 million affected persons, they are more common than any other mental illness among persons in Europe aged 14 to 65 . Women are affected two to three times as commonly as men (1).

Anxiety disorders often begin in childhood or adolescence (e5). This is particularly true for specific phobias and social phobia. Selective mutism can arise as early as a child's third year. Most children go through a transient phase of non-pathological aversion to strangers, often beginning at the age of eight or nine months. In $2-3 \%$ of children, marked separation anxiety persists into the preschool or schoolage years. Treatment is indicated if separation anxiety impairs the normal development of the child, e.g., by making it impossible for the child to have important social experiences.

The World Health Organization (WHO) reported that, in 2015, anxiety disorders ranked in sixth place among all mental and somatic illnesses worldwide as a cause of so-called years lived with disability (YLD), and in fourth place in highly developed countries; they are thus among the chronic illnesses with the greatest impact on patients' lives (2). Specific phobias are the most common type of anxiety disorder.

\section{Taxonomy and manifestations}

The anxiety disorders, as classified in the International Classification of Diseases (ICD-10) (3), comprise the phobic disorders, including agoraphobia with (F40.00) or without panic disorder (F40.01), social phobia (F40.1), and the specific phobias (F40.2), as well as other anxiety disorders, including panic disorder (F41.0), generalized anxiety disorder (F41.1), and mixed anxiety and depression (F41.2) (Table 1). In the current edition of the Diagnostic and Statistical Manual of Mental Disorders (DSM-5) (e6), which is the main reference text for the taxonomy of mental illnesses in the USA, separation anxiety disorder and selective mutism are newly classified as anxiety disorders. These were previously considered illnesses restricted to childhood and adolescence, but are now held to be relevant in adulthood as well. The upcoming ICD-11 can be previewed in a beta version that is available online. In this classification, too, separation anxiety disorder and selective mutism will appear for the first time among the (adult) anxiety disorders (4).
Separation anxiety disorder is characterized by persistent and excessive anxiety associated with separation from the patient's most significant other(s), to an inappropriate extent from the developmental psychological point of view. Its lifetime prevalence is $4.8 \%$. It is usually initially diagnosed in childhood, but recent studies have shown that it is increasingly common in adulthood as well. For instance, an evaluation of the World Mental Health Survey conducted by the World Health Organization (WHO) revealed that, among 38993 adults in 18 different countries, the age of onset of separation anxiety disorder was over 18 years in $43.1 \%$ of cases $(5,6)$.

Selective mutism is a rare anxiety disorder that usually presents in childhood or adolescence. The diagnostic evaluation for this disorder often takes place only after the child has started school. Persons suffering from selective mutism are persistently unable to speak in certain situations, even though they can do so in other situations, usually when with their families. If the patient emits no phonetic expressions of any kind (e.g., coughing, crying, laughing, or speaking) in any situation whatsoever, the term "total mutism" is used. According to the DSM-5 (e6), the point prevalence of selective mutism lies between $0.03 \%$ and $1 \%$. No data are yet available from representative epidemiological studies of entire populations; the wide disparity of prevalence estimates is presumably due to the diversity of settings in which the data were acquired (hospitals, schools, the population at large) (e6). Approximately one-third of sufferers have persistent symptoms into adulthood (7). Unfortunately, no valid data are available on the frequency of this disorder as a function of age.

\section{Sequential comorbidity}

Anxiety disorders are associated with high parallel comorbidity with other anxiety disorders. In addition, individuals with an anxiety disorder are at elevated risk of developing further anxiety disorders over time. A meta-analysis of 20 studies revealed that, among children with separation anxiety, the risk of developing a panic disorder later on is more than three times higher than in children without separation anxiety (8). The epidemiological term for such longitudinal associations is "sequential comorbidity" (Figure). This exists not only within the anxiety disorders among themselves, but beyond them as well: anxiety disorders elevate the risk of developing other mental illnesses such as depression or substance-related disorders (9). For example, a Danish study on a cohort of 3380059 persons showed that patients with anxiety disorders, in
Age of presentation

Anxiety disorders often begin in childhood, adolescence, or early adulthood.

\section{Sequential comorbidity}

Anxiety disorders elevate the risk of developing other mental illnesses. 
comparison to the general population, have an adjusted incidence rate ratio (IRR) of 3.0 for a depressive episode (95\% confidence interval [CI]: $[2.8 ; 3.1]$ ) and an IRR of 5.0 for a recurrent depressive disorder $(95 \% \mathrm{CI}$ : $[4.8 ; 5.2])$ (10).

Anxiety disorders also play a major role in the development and prognosis of somatic diseases. In a longitudinal study of 293 persons (median age: 55 years) who were in good cardiovascular and autoimmune health, amygdalar activation on ${ }^{18} \mathrm{~F}$-fluorodexoyglucose positron emission tomography/computed tomography $\left({ }^{18}\right.$ F-PET-CT $)$ - a key radiological finding that is typical of anxiety disorders-was found to be associated with an elevated risk of developing cardiovascular disease in a subsequent observation period of 3.7 years (median duration). There were a total of 22 new cases of cardiovascular disease and a calculated hazard ratio (HR) of 1.6 (95\% CI: [1.27; $1.98]$ ), i.e., a $60 \%$ elevation of the risk of developing a cardiovascular disease for each increase of the amygdalar signal by one standard deviation. This association seems to be mediated by elevated bonemarrow activity and arterial inflammation. When interpreting these results, one must bear in mind that amygdalar activation is a general measure of emotional processes and is not specific for anxiety or for anxiety disorders (11).

In a meta-analysis of 16 cohort studies (Health Survey for England [HSE], Scottish Health Survey [SHS]) involving a total of 163363 men and women who stated that they did not have cancer at the time of inclusion in the study, it was found, after correction for age, sex, level of education, smoking status, and alcohol consumption, that persons with a high anxiety/depression score at the time of inclusion were significantly more likely to die of cancer in an ensuing observation period of 9.5 years (mean duration; 4353 deaths overall; multivariable adjusted hazard ratio $1.32,95 \%$ CI: $[1.18 ; 1.48])$, compared to persons with a low anxiety/depression score (GHQ-12: 0-6). This was particularly the case for colorectal, prostatic, pancreatic, and esophageal cancer and for leukemia. Aside from other, possibly overlooked confounding variables, it cannot be ruled out that persons with a high anxiety/depression score at the time of inclusion already had an as yet undetected subclinical malignancy, leading to increased mental stress in the sense of what epidemiologists call "reverse causality." To limit the influence of initially occult malignancies on the study findings, patients who died in the first five years of the observation period were excluded from the analysis (12).

\section{Generalized anxiety disorder}

This type of anxiety disorder manifests itself with anxious worrying, tension, and fears about everyday events and problems.
TABLE 1

Clinical manifestations of anxiety disorders according to ICD-10 (4)

\begin{tabular}{l|l}
$\begin{array}{l}\text { Anxiety disorder } \\
\text { Generalized anxiety } \\
\text { disorder (F41.1) }\end{array}$ & $\begin{array}{l}\text { Anxious worry, tension, and fears about everyday events } \\
\text { and problems }\end{array}$ \\
\hline $\begin{array}{l}\text { Panic disorder } \\
\text { (F41.0) }\end{array}$ & $\begin{array}{l}\text { Repeated and unexpected panic attacks (anxiety attacks) } \\
\text { with both physical manifestations (palpitations, dyspnea, } \\
\text { diaphoresis, paresthesiae, nausea) and mental ones (fear } \\
\text { ranging to mortal fear, fear of losing control, feeling of alien- } \\
\text { ation) }\end{array}$ \\
\hline $\begin{array}{l}\text { Panic disorder with } \\
\text { agoraphobia (F40.01) }\end{array}$ & Repeated and unexpected panic attacks plus agoraphobia \\
\hline $\begin{array}{l}\text { Agoraphobia } \\
\text { (F40.0) }\end{array}$ & $\begin{array}{l}\text { Phobias involving fears of leaving home, entering shops, } \\
\text { crowds and public places, or traveling alone in trains, buses } \\
\text { or planes }\end{array}$ \\
\hline $\begin{array}{l}\text { Social phobia } \\
\text { (F40.1) }\end{array}$ & $\begin{array}{l}\text { Fear of scrutiny by other people leading to avoidance of } \\
\text { social situations. More pervasive social phobias are usually } \\
\text { associated with low self-esteem and fear of criticism. They } \\
\text { may present as a complaint of blushing, hand tremor, } \\
\text { nausea, or urgency of micturition }\end{array}$ \\
\hline $\begin{array}{l}\text { Specific phobia } \\
\text { (F40.2) }\end{array}$ & $\begin{array}{l}\text { Fear and/or avoidance of certain objects or situations. } \\
\text { Types: animals, natural events (thunder, etc.), blood, } \\
\text { injections, injury, or other triggering situations or objects }\end{array}$ \\
\hline $\begin{array}{l}\text { Selective mutism } \\
\text { (F94.0) }\end{array}$ & $\begin{array}{l}\text { Language competence in some situations, but failure to } \\
\text { speak in other (definable) situations }\end{array}$ \\
\hline $\begin{array}{l}\text { Separation anxiety } \\
\text { Unrealistic and persistent worry about adverse events that } \\
\text { might befall the patient's most significant others, or about } \\
\text { the potential loss of same }\end{array}$ \\
\hline
\end{tabular}

The early detection and treatment of anxiety disorders may thus have a secondary preventive effect against further mental and somatic diseases as well as a beneficial influence on the course of somatic disease. The association between early detection and prevention remains to be examined in randomized controlled trials.

\section{Etiology}

Anxiety disorders are among the so-called complex genetic diseases characterized by a complex pathogenetic interaction of environmental factors with multiple genetic variants at different chromosomal loci. Family studies have shown that first-degree relatives of patients with panic disorders have a three- to fivefold elevation of the risk of developing such a disorder themselves, compared to the general population. Familial clustering is also seen in generalized anxiety disorder and in the specific phobias. The heritability of

Panic disorders are characterized by:

Repeated and unexpected panic attacks (anxiety attacks) with both physical manifestations (palpitations, dyspnea, diaphoresis, paresthesiae, nausea) and mental ones (fear ranging to mortal fear, fear of losing control, feeling of alienation). 
anxiety disorders, i.e., the degree of participation of genetic factors in their development, lies in the range of $30-67 \%$, with the remainder of the variation accounted for by individual negative environmental factors, such as life events (13). These include, for example (14):

- Abuse and neglect (emotional and/or physical)

- Sexual violence

- Chronic illness

- Traumatic injuries

- Deaths of significant others

- Separation and divorce

- Financial difficulties.

On the other hand, positive environmental factors, effective coping strategies, secure bonding styles, supportive learning experiences, and a good social support network can increase resilience, even in the presence of a genetic risk-factor constellation. Meanwhile, the role of epigenetic mechanisms in the causation of anxiety disorders is gaining increased attention. Epigenetic mechanisms are biochemical processes, such as, for example, DNA methylation or histone acetylation, that act on DNA or its spatial structure without changing the DNA sequence per se. They play an important role in the regulation of gene activity and display marked temporal plasticity, being alterable by life events or even by psychotherapeutic intervention. Epigenetic processes may, therefore, play a key role in tipping the balance between risk factors and resilience, leading to an adaptive or maladaptive outcome: it is perhaps the integration of the genetic risk together with the environmentally determined risk by way of epigenetic processes that ultimately determines whether an anxiety disorder will arise. Individual epigenetic effects, like individual genetic effects, are small (15). Initial epigenetic pilot studies on small groups of patients with anxiety disorders have revealed altered patterns of DNA methylation in risk genes for these disorders, and it seems that successful psychotherapy or pharmacotherapy leads to the normalization of these altered epigenetic patterns (16).

The neuronal structures that participate in the anxiety network include the amygdala, whose efferent fibers to the hypothalamus, the locus ceruleus, and the periaqueductal gray play a role in the regulation of the central and peripheral manifestations of the anxiety response, and areas of prefrontal cortex and the anterior cingulate gyrus that exert an inhibitory effect on the amygdala $(17,18)$. Further brain areas belonging to the anxiety network are the insula, which integrates interoceptive signals, and the bed nucleus of the stria terminalis, which has recently been ascribed a central role in what is called "sustained anxiety" - a typical feature of generalized anxiety disorder, panic disorder, and social anxiety disorder (19).

Learning plays a major role in the development and maintenance of anxiety disorders, as well as in their treatment. Classical and operant conditioning exert their effects, and avoidant behavior contributes to the maintenance of the disorder. There also seems to be an evolutionarily determined capacity to mount an excessive anxiety reaction to the objects of the specific phobias, encouraging the development of these phobias; Seligman introduced the term "preparedness" for this capacity (e8). Personality traits, too, especially neuroticism, are related to the development of anxiety disorders (e9). Extinction learning via in-vivo exposure is now considered to be a form of relearning, rather than the erasure (unlearning) of previously acquired content.

\section{Treatment}

As recommended in the $\mathrm{S} 3$ guideline on the treatment of anxiety disorders issued in May 2014 (20), psychotherapy and pharmacotherapy should both be offered, and the two are considered comparably effective. Decisions about treatment should be made in the light of the severity of the disorder, the preference of the informed patient, the expected latency and durability of the treatment effect, the expected side effects, and the availability of the treatment in question. If one form of treatment proves to be ineffective, the other (or a combination of both) should be tried. Only for the specific phobias is there very good evidence, and therefore a very strong recommendation, for psychotherapy alone; drugs are not indicated in the treatment of the specific phobias.

For all types of anxiety disorder, cognitive behavioral therapy is the type of psychotherapy for which there is the strongest evidence and which receives the highest-level recommendation (Ia; A). Initial randomized controlled trials have confirmed the clinical efficacy of psychodynamic therapies, e.g., in social phobia (21). Nonetheless, psychodynamic therapy receives evidence level IIa in the current German guidelines because of the incomplete state of the data from clinical trials, along with the recommendation that this type of psychotherapy should be offered if cognitive behavioral therapy has been ineffective or is unavailable, or if an informed patient expresses a preference for it (20). The specifics of cognitive behavioral therapy vary depending on the particular

\section{Genetic factors}

The heritability of anxiety disorders, i.e., the degree of participation of genetic factors in their development, lies in the range of $30-67 \%$, with the remainder of the variation accounted for by individual negative environmental factors, such as life events.

\section{Treatment}

Anxiety disorders can be treated with psychotherapy, drugs, or both. 


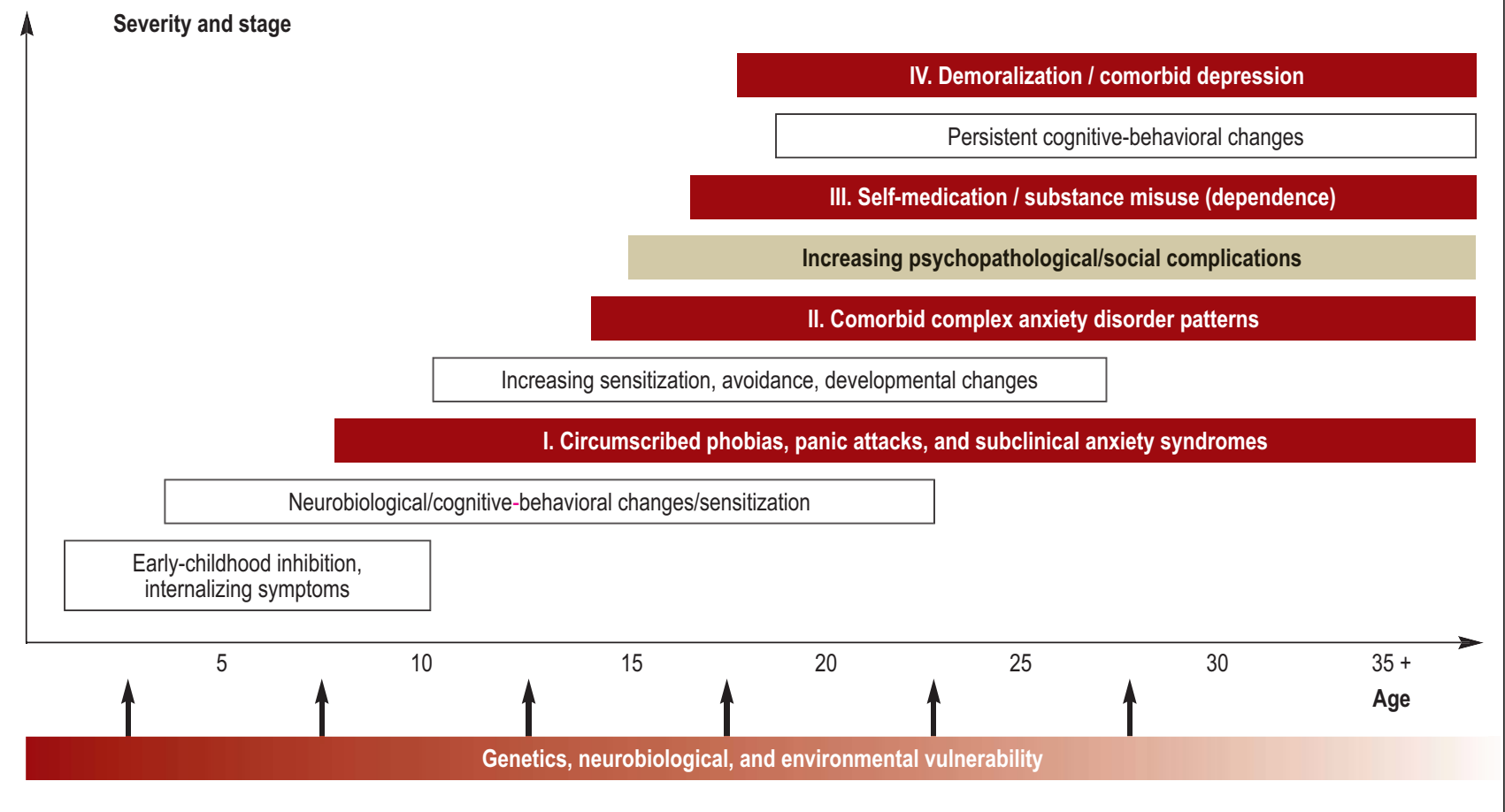

Anxiety disorders presenting early in life increase the risk of developing other mental illnesses later on in life (sequential comorbidity) (modified from [e7] and reprinted with the kind permission of John Wiley, publishers)

anxiety disorder being treated, with the common element that the patient must make the experience that his or her situationally induced anxiety is unfounded and the situation actually harmless. This is best achieved through exposure under the supervision of a therapist (22), in the course of which the patient must experience habituation of the anxiety response, so that the central fear underlying it is refuted. Exposure in virtual reality is now increasingly a part of cognitivebehavioral therapeutic interventions (23).

Cognitive behavioral therapy has been found to have a moderately strong beneficial effect against all types of anxiety disorder compared to a placebo drug (Cohen's $d=0.57$ ); the same is true of pharmacotherapy (e.g., sertraline, $\mathrm{d}=0.54$; venlafaxine, $\mathrm{d}=0.50$ ) (24). If only the before vs after changes are studied, remarkably strong effects are found for pharmacotherapy (selective serotonin and norepinephrine reuptake inhibitors [SNRI], $d=2.25)$ compared to cognitive behavioral therapy $(\mathrm{d}=1.30)(24)$. Combin-

\section{Psychotherapy}

Cognitive behavioral therapy is the tpe of psychotherapy of first choice in the treatment of the anxiety disorders. ing pharmacotherapy with psychotherapy is usually not superior to monotherapy with either one of the two options alone (20). In a meta-analysis of the few available studies with long follow-up periods, Bandelow et al. (25) concluded that further symptomatic improvement took place 26-104 weeks after the end of cognitive behavioral therapy. After pharmacotherapy, there was no worsening in the follow-up period, but this difference compared to cognitive behavioral therapy did not reach statistical significance.

The drugs with the highest level of supporting evidence are the selective serotonin reuptake inhibitors (SSRI) and SNRI, as well as the calcium-channel modulator pregabalin for generalized anxiety disorder (Table 2).

In the informed-consent discussion, the patient should not only be informed of the specific side effects of the drug class(es) to be prescribed, but should also be told that the effect of antidepressant drugs may be delayed by a latency of approximately two

\section{Treatment with psychoactive drugs}

The drugs most commonly used are the selective serotonin reuptake inhibitors (SSRI) and the selective noradrenaline ruptake inhibitors (SNRI). 
weeks (range: 1-6 weeks), and that these drugs may, in fact, initially worsen nervousness, agitation, and anxiety. They should therefore be given at a low dose at first, with gradual upward titration (Box).

A common question in clinical practice is how long drug therapy should be continued in order to prevent a relapse. The response rates are generally high (ca. $80 \%$ ), but too early discontinuation of medication is associated with non-negligible relapse rates. Among patients with panic disorder, for example, a relapse is seen in $15-50 \%$ within 6-12 months of the discontinuation of tricyclic antidepressants, SSRI, or venlafaxine. It is therefore recommended that maintenance therapy with SSRI or SNRI be continued for at least 6-12 months after the end of the acute phase, at the effective final dose that was attained. Any attempt to discontinue medication should be gradual, e.g., over the course of 12 weeks if the duration of treatment until now has been 40 weeks (27).

Benzodiazepines are approved in Germany for the acute treatment of "states of tension, excitation, and anxiety." Nonetheless, the German guidelines on the treatment of anxiety disorders discuss the use of benzodiazepines for this purpose in decidedly critical terms: "Benzodiazepines are effective against panic disorder/agoraphobia/generalized anxiety disorder/ social phobia (Ia; guideline adaptation). They should nonetheless not be offered to patients with panic disorder/agoraphobia/generalized anxiety disorder/ social phobia because of their serious side effects (development of dependence, etc.). They can be used for a limited time after careful evaluation of the risks and benefits in exceptional cases, e.g., patients with severe cardiac disease, contraindications for standard drugs, suicidality, and other conditions." The discontinuation of benzodiazepines after they have been taken for months or years, as is often the case, is a special challenge in the treatment of patients with anxiety disorders (28). Drug discontinuation must often take place in an inpatient setting, and only a few of the pertinent treatment recommendations are supported by adequate evidence.

While cognitive behavioral therapy and psychopharmacotherapy are considered first-line treatments for anxiety disorders, further treatment strategies have been studied and applied in routine clinical practice in recent years, such as the following:

- Metacognitive therapy (29)

- Acceptance and commitment therapy (ACT) (30)

- Mindfulness-based techniques (31)

\section{Benzodiazepines}

Benzodiazepines are approved in Germany for the acute treatment of "states of tension, excitation, and anxiety." Nonetheless, the German guidelines on the treatment of anxiety disorders discuss the use of benzodiazepines for this purpose in decidedly critical terms because of their marked side effects.
- Noninvasive stimulation techniques, such as repetitive transcranial magnetic stimulation (rTMS) or transcranial direct-current stimulation (tDCS) (32)

- Physical activity and exercise (33).

A systematic review of the literature is needed so that the relevance of new studies for the guideline recommendations can be appropriately assessed.

We find the use of physical activity and exercise as a treatment of anxiety disorders to be particularly interesting. This mode of treatment is inexpensive and has few undesired effects; it should be applied in combination with the first-line therapies (not as the sole intervention) and is used much too rarely in routine clinical practice (33). Very strong pre/post effect strengths of $g=-1.23$ (24) seem impressive but have not been reproduced in studies with active control groups (34). Even single units of endurance training can have an anxiolytic effect (e13-e15) or perhaps reinforce the effect of exposure therapy (35).

Aside from drug therapy of the types discussed, clinical practice guidelines also contain recommendations for psychological treatments of anxiety disorders in the primary medical care setting. The essential building-blocks of treatment are (20):

- counseling,

- psycho-education about anxiety and anxiety disorders,

- instructions for anxiety-confronting exercises in real-life situations, and

- the use of self-help manuals (20).

The primary care physician and the patient work jointly to develop a gradually intensifying treatment plan (participative decision-making). With the primary care physician's attentive personal support and counseling, the patient carries out specific anxietyreducing exercises (36). Anxiety-confronting exercises are performed in controlled fashion according to the principles of cognitive behavioral therapy (CBT). Patients with panic disorder, in particular, are confronted with so-called interoceptive stimuli (as an exercise, including, for instance, 60 seconds of hyperventilation under supervision); patients with agoraphobia are confronted with so-called situational stimuli (e.g., taking a train ride by oneself). It is important for the patient to discuss the exercise afterward with the physician in order to reinforce the new experience and solidify the associated learning achievement. The stimuli that were originally felt to be anxiety-producing are now judged more appropriately. Trained medical practice assistants can serve as

The essential components of the treatment of panic disorder with agoraphobia are:

- Counseling

- Psycho-education about anxiety and anxiety disorders

- Anxiety-confronting exercises in real-life situations

- Self-help manuals 
The pharmacotherapy of anxiety disorders, according to the German guidelines (20)

\begin{tabular}{|c|c|c|c|}
\hline $\begin{array}{l}\text { Evidence level/ } \\
\text { recommendation grade }{ }^{* 1}\end{array}$ & Active substance class & Drug & Daily dose \\
\hline \multicolumn{4}{|l|}{ Social phobia } \\
\hline \multirow[t]{3}{*}{ la; $A$} & \multirow[t]{3}{*}{ SSRI } & Escitalopram & $10-20 \mathrm{mg}$ \\
\hline & & Paroxetine & $20-50 \mathrm{mg}$ \\
\hline & & Sertraline & $50-150 \mathrm{mg}$ \\
\hline la; A & SNRI & Venlafaxine & $75-225 \mathrm{mg}$ \\
\hline $\mathrm{CCP}$ & MAO inhibitors & Moclobemide & $300-600 \mathrm{mg}$ \\
\hline \multicolumn{4}{|l|}{ Panic disorder } \\
\hline \multirow[t]{4}{*}{ la; $\mathrm{A}$} & \multirow[t]{4}{*}{ SSRI } & Citalopram & $20-40 \mathrm{mg}$ \\
\hline & & Escitalopram & $10-20 \mathrm{mg}$ \\
\hline & & Paroxetine & $20-50 \mathrm{mg}$ \\
\hline & & Sertraline & $50-150 \mathrm{mg}$ \\
\hline la; A & SNRI & Venlafaxine & $75-225 \mathrm{mg}$ \\
\hline la; B & TCA & Clomipramine & $75-250 \mathrm{mg}$ \\
\hline \multicolumn{4}{|l|}{ Generalized anxiety disorder } \\
\hline \multirow[t]{2}{*}{ la; $\mathrm{A}$} & \multirow[t]{2}{*}{ SSRI } & Escitalopram & $10-20 \mathrm{mg}$ \\
\hline & & Paroxetine & $20-50 \mathrm{mg}$ \\
\hline \multirow[t]{2}{*}{ la; A } & \multirow[t]{2}{*}{ SNRI } & Venlafaxine & $75-225 \mathrm{mg}$ \\
\hline & & Duloxetine & $60-120 \mathrm{mg}$ \\
\hline $\mathrm{la} ; \mathrm{B}^{* 2}$ & Anticonvulsants & Pregabalin & $150-600 \mathrm{mg}$ \\
\hline $\mathrm{lb} ; 0$ & Anxiolytic drugs (tricyclic) & Opipramol & $50-300 \mathrm{mg}$ \\
\hline $\mathrm{lb} ; 0$ & Azapirones & Buspirone & $15-60 \mathrm{mg}$ \\
\hline
\end{tabular}

${ }^{* 1}$ according to the German guidelines

${ }^{* 2}$ Case studies indicate that pregabalin has a potential for abuse, mainly in patients with substance-related disorders and above all in opiate-dependent patients

(26). It is accordingly recommended in the German guidelines that patients with substance-related disorders, and particularly those who are addicted to multiple drugs, should not be treated with pregabalin. If a patient does not respond to a drug or cannot tolerate it, the next step may be a switch from one standard drug to another (e.g., from an SSRI to an SSNRI; in generalized anxiety disorder, from an SSRI to pregabalin) or a switch to a nonstandard drug, such as one with a lower evidence level or recommendation grade (e.g., moclobemide in social phobia), or to one that is not approved for the treatment of anxiety disorders, but has nonetheless been reported to be clinically effective (e.g., quetiapine, agomelatine, lavender oil, and, in some cases, mirtazapine).

$\mathrm{CCP}=$ clinical consensus point; $\mathrm{SSRI}$ = selective serotonin reuptake inhibitors; SNRI = selective serotonin and norepinephrine reuptake inhibitors;

$\mathrm{MAO}=$ monoamine oxidase; $\mathrm{TZA}=$ tricyclic antidepressants

case managers to help the patient carry out these exercises: they telephone the patient regularly to record the patient's current disease manifestations with the aid of a brief symptom checklist. This list is at the center of communication between the physician, the patient, and the practice assistant (37); it permits rapid assessment of the patient's situation and reliable transmission of this information to the physician, who can then respond in timely fashion. If the symptoms

\section{Exercise therapy}

Exercise has an anxiolytic effect and is therapeutically useful in both the short term and the long term. fail to improve rapidly under the care of the primary care physician, a psychiatrist or psychotherapist should be consulted without delay. It has been shown that the ambulatory treatment of patients with panic disorder and agoraphobia with exposure therapy is more effective when carried out under direct supervision than when carried out by the patient alone according to directions (22). Supervision of the exposure places a heavy psychological demand on the 
BOX

\section{The off-label use of drugs that have not been approved for the treatment of anxiety disorders}

The atypical antipsychotic drug quetiapine has not been approved for the treatment of anxiety disorders. Still, a meta-analysis of three randomized, doubleblind, placebo-controlled trials of this drug for the treatment of generalized anxiety disorder (GAD), given for a period of 10 weeks in each trial, showed that it is significantly more effective than placebo in the 50 to $300 \mathrm{mg} /$ day dose range, albeit with an unfavorable profile of metabolic side effects (e10).

Agomelatine acts as an agonist at melatonin MT1- and MT2-receptors and as an antagonist at the serotonin $2 \mathrm{C}$ receptor. Multiple studies published from 2008 onward have shown it to be well tolerated and highly effective against GAD in the $25-50 \mathrm{mg} /$ day dose range (e11), yet this drug has not been approved for the treatment of anxiety disorders either.

Silexan, a patented active substance derived from lavender oil, has been approved since 2009 in Germany for the treatment of subsyndromal anxiety and tension states at a daily dose of $80 \mathrm{mg}$, but not for the treatment of anxiety disorders. Nonetheless, randomized controlled trials (RCTs) have shown its effectiveness against GAS and so-called mixed anxiety and depression (e12).

therapist as well (38); this can be observed in the activation of the stress hormone system, particularly with massive exposure (flooding) (39).

\section{Prevention}

The development and assessment of preventive measures against anxiety disorders should have a high priority in view of these disorders' high prevalence and chronicity, the severity of the suffering that they cause, their high socioeconomic costs, and their role as precursors of depression and substance-abuse disorders and as complicating factors in somatic disease (40). Universal preventive measures, applied regardless of the risk status of the individual, might prevent many cases of clinically manifest anxiety disorders, even if their individual effects were not very strong; yet their application to large, unselected target groups would be both very expensive and very labor-intensive. The alternative lies in targeted programs, or, in other words, selective primary preventive measures, such as the Cool Little Kids program or the Friends program. These measures are particularly effective in preventing the development of clinically overt anxiety disorders in high-risk groups in the critical temporal window of childhood and adolescence. For example, a longitudinal randomized controlled trial showed that the Cool
Little Kids program was significantly superior to control (no treatment) in a population of 3- to 5-year-old preschool children: the preventive intervention significantly lowered the incidence of anxiety disorders at 12 $(p=0.03), 24(p=0.03)$, and $36(p=0.01)$ months, and even after a further follow-up period of 11 years - but then only among the girls, who were about 15 years old by that time (Cohen's $\mathrm{d}=0.55, \mathrm{p}=0.04)(\mathrm{e} 16, \mathrm{e} 17)$. Targeted prevention in persons who already display subclinical symptoms has been shown to significantly lessen the rate of development of clinically relevant anxiety disorders and is thus probably the most costeffective primary measure. Meta-analyses have revealed low effect strengths for the prevention of anxiety; targeted measures were found to be somewhat more effective than universal ones right after the intervention (Cohen's $d=0.26$ versus 0.17 [e18, e19]). The prevention manuals now available in the Germanspeaking countries include, for example, the Friends program; the Separation Anxiety Program for Families (Trennungsangstprogramm für Familien, TAFF); the Being Brave with Til Tiger program (Mutig werden mit Til Tiger); and the Health and Optimism Program (Gesundheits- und Optimismus-Programm). The encouraging initial data imply that preventive measures against mental illnesses, and in particular against anxiety disorders, which are very common and socioeconomically relevant, urgently need to be studied further, systematically, and in detail. If their effects can be confirmed, these measures should be implemented in timely fashion in the healthcare system.

\section{Conflict of interest statement}

The authors declare that no conflict of interest exists.

Manuscript submitted on 30 April 2018, revised version accepted on 31 July 2018.

Translated from the original German by Ethan Taub, M.D.

\section{References}

1. Wittchen HU, Jacobi F, Rehm J, et al: The size and burden of menta disorders and other disorders of the brain in Europe 2010. Eur Neuropsychopharmacol 2011; 9: 655-79.

2. WHO: Depression and Other Common Mental Disorders: Global Health Estimates. Geneva: World Health Organization; 2017. Licence: CC BY-NC-SA 3.0 IGO (http://apps.who.int/iris/bitstream/ handle/10665/254610/WHO-MSD-MER-2017.2-eng.pdf;jsessionid=829EAD6A4E0473EBDE28F4FD23B8D556? sequence=1) (last accessed on 22 August 2018).

3. Dilling H: Internationale Klassifikation Psychischer Störungen: ICD-10 Kapitel V (F); Klinisch-diagnostische Leitlinien. $8^{\text {th }}$ revised edition ICD10-GM 2011. Bern: Huber 2011.

4. WHO: ICD-11. https://icd.who.int/dev11//-m/en. (last accessed on 22 August 2018).

\section{Exposure under the supervision of a therapist}

It has been shown that the outpatient treatment of patients with panic disorder and agoraphobia with exposure therapy is more effective when carried out under direct supervision than when carried out by the patient alone.

\section{Prevention manuals}

The prevention manuals now available in the Germanspeaking countries include, for example, the Friends program; the Separation Anxiety Program for Families (TAFF); the Being Brave with Til Tiger program; and the Health and Optimism Program. 
5. Silove D, Alonso J, Bromet E, et al.: Pediatric-onset and adult-onset separation anxiety disorder across countries in the world mental health survey. Am J Psychiatry 2015; 172: 647-56.

6. Baldwin DS, Gordon R, Abelli M, Pini S: The separation of adult separation anxiety disorder. CNS Spectrums 2016; 21: 289-94.

7. Rogoll J, Petzold M, Ströhle A: Selektiver Mutismus. Nervenarzt 2018; 89 : 591-602.

8. Kossowsky J, Pfaltz MC, Schneider S, Taeymans J, Locher C, Gaab J: The separation anxiety hypothesis of panic disorder revisited: a meta-analysis. Am J Psychiatry 2013; 170: 768-81.

9. Grant BF, Goldstein RB, Saha TD, et al.: Epidemiology of DSM-5 alcohol use disorder: results from the national epidemiologic survey on alcohol and related conditions III. JAMA Psychiatry 2015; 72: 757-66.

10. Meier SM, Petersen L, Mattheisen M, Mors O, Mortensen PB, Laursen TM: Secondary depression in severe anxiety disorders: a population-based cohort study in Denmark. Lancet Psychiatry 2015; 2: 515-23.

11. Tawakol A, Ishai A, Takx RA, et al.: Relation between resting amygdalar activity and cardiovascular events: a longitudinal and cohort study. Lancet 2017; 389: 834-45.

12. Batty GD, Russ TC, Stamatakis E, Kivimäki M: Psychological distress in relation to site specific cancer mortality: pooling of unpublished data from 16 prospective cohort studies. BMJ 2017; 356: j108.

13. Gottschalk MG, Domschke K: Novel developments in genetic and epigenetic mechanisms of anxiety. Curr Opin Psychiatry 2016; 29: 32-8.

14. Klauke B, Deckert J, Reif A, Pauli P, Domschke K: Life events in panic disorder-an update on "candidate stressors“. Depress Anxiety 2010; 27: 716-30.

15. Schiele MA, Domschke K: Epigenetics at the crossroads between genes, environment and resilience in anxiety disorders. Genes Brain Behav 2018; 17: e12423.

16. Ziegler C, Richter J, Mahr M, et al.: MAOA gene hypomethylation in panic disorder-reversibility of an epigenetic risk pattern by psychotherapy. Transl Psychiatry 2016; 6: e773.

17. Bandelow B, Baldwin D, Abelli M, et al.: Biological markers for anxiety disorders, OCD and PTSD—a consensus statement. Part I: neuroimaging and genetics. World J Biol Psychiatry 2016; 17: 321-65.

18. Bandelow B, Baldwin D, Abelli M, et al.: Biological markers for anxiety disorders, OCD and PTSD: a consensus statement. Part II: neurochemistry, neurophysiology and neurocognition. World J Biol Psychiatry 2017; 18: 162-214.

19. Lebow MA, Chen A: Overshadowed by the amygdala: the bed nucleus of the stria terminalis emerges as key to psychiatric disorders. Mol Psychiatry 2016; 4 450-63.

20. Bandelow B, Wiltink J, Alpers GW, et al.: Deutsche S3-Leitlinie Behandlung von Angststörungen. www.awmf.org/uploads/tx szleitlinien/051-028| S3 Angstst\%C3\%B6rungen_2014-05_2.pdf (last accessed on 13 August 2018)

21. Leichsenring F, Salzer S, Beutel ME, et al.: Psychodynamic therapy and cognitivebehavioral therapy in social anxiety disorder: a multicenter randomized controlled trial. Am J PSychiatry 2013; 170: 759-67.

22. Gloster AT, Wittchen HU, Einsle F, et al.: Psychological treatment for panic disorder with agoraphobia: a randomized controlled trial to examine the role of therapistguided exposure in situ in CBT. J Consult Clin Psychol 2011; 79: 406-20.

23. Diemer J, Mühlberger A, Pauli P, Zwanzger P: Virtual reality exposure in anxiety disorders: impact on psychophysiological reactivity. World J Biol Psychiatry 2014; 15: 427-42.

24. Bandelow B, Reitt M, Röver C, Michaelis S, Görlich Y, Wedekind D: Efficacy of treatments for anxiety disorders: a meta-analysis. Int Clin Psychopharmacol 2015; 30: 183-92.

25. Bandelow B, Sagebiel A, Belz M, Görlich Y, Michaelis S, Wedekind D: Enduring effects of psychological treatments for anxiety disorders: meta-analysis of follow-up studies. Br J Psychiatry 2018; 212: 333-8.

26. Bonnet U, Scherbaum N: How addictive are gabapentin and pregabalin? A systematic review. Eur Neuropsychopharmacol 2017; 27: 1185-215.

27. Perna G, Alciati A, Riva A, Micieli W, Caldirola D: Long-term pharmacological treatments of anxiety disorders: an updated systematic review. Curr Psychiatry Rep 2016; 18: 23.

28. Soyka M: Treatment of benzodiazepine dependence. N Engl J Med 2017; 376: 1147-57.

29. Normann N, Emmerik AAP, Morina N: The efficacy of metacognitive therapy for anxiety and depression: a meta-analytic review. Depression Anxiety 2014; 31 402-11.

30. Gloster AT, Sonntag R, Hoyer J, et al.: Treating treatment-resistant patients with panic disorder and agoraphobia using psychotherapy: a randomized controlled switching trial. PPS 2015; 84: 100-9.

31. Rodrigues MF, Nardi AE, Levitan M: Mindfulness in mood and anxiety disorders: a review of the literature. Trends Psychiatr Psychoth 2017; 39: 207-15.

32. Zwanzger P, Fallgatter AJ, Zavorotnyy M, Padberg F: Anxiolytic effects of transcranial magnetic stimulation-an alternative treatment option in anxiety disorders? J Neural Transm 2009; 116: 767-75.

33. Ströhle A: Sports psychiatry: mental health and mental disorders in athletes and exercise treatment of mental disorders. Eur Arch Psychiatry Clin Neurosci 2018 [Epub ahead of print].
34. Gaudlitz K, Plag J, Dimeo F, Ströhle A: Aerobic exercise training facilitates the effectiveness of cognitive behavioral therapy in panic disorder. Depression Anxiety 2015; 32: 221-8.

35. Bischoff S, Wieder G, Einsle F, et al.: Running for extinction? Aerobic exercise as an augmentation of exposure therapy in panic disorder with agoraphobia. J Psychiatr Res 2018; 101: 34-41.

36. Archer J, Bower P, Gilbody S, et al.: Collaborative care for depression and anxiety problems. Cochrane Database Syst Rev 2012; 10: CD006525.

37. Hiller TS, Freytag A, Breitbart J, et al.: Die Jena Angst-Monitoring-Liste (JAMoL) ein Instrument zur evidenzbasierten Behandlung von Panikstörung mit oder ohne Agoraphobie in der Hausarztpraxis. Z Ev Fortbil Qualität Gesundheitsw 2018; 131-132: 28-37.

38. Schumacher S, Gaudlitz K, Plag J, et al.: Who is stressed? A pilot study of salivary cortisol and alpha-amylase concentrations in agoraphobic patients and their novice therapists undergoing in vivo exposure. Psychoneuroendocrinology 2014; 49: 280-9.

39. Schumacher S, Miller R, Fehm L, Kirschbaum C, Fydrich T, Ströhle A: Therapists' and patients' stress responses during graduated versus flooding in vivo exposure in the treatment of specific phobia: a preliminary observational study. Psychiatry Res 2015; 230: 668-75

40. Domschke K, Deckert J: Prävention von Angststörungen. Handbuch Prävention psychischer Störungen. Stuttgart: Schattauer 2017.

\section{Corresponding author}

Prof. Dr. med. Andreas Ströhle

Charité - Universitätsmedizin Berlin, corporate member of the Freie Universität Berlin

Humboldt-Universität zu Berlin, and Berlin Institute of Health

Department of Psychiatry and Psychotherapy

Klinik für Psychiatrie und Psychotherapie, Campus Charité Mitte

Charitéplatz 1, 10117 Berlin, Germany

andreas.stroehle@charite.de

- Supplementary material

For eReferences please refer to:

www.aerzteblatt-international.de/ref 3718

\section{Further information on CME}

- Participation in the CME certification program is possible only over the Internet: cme.aerzteblatt.de. This unit can be accessed until 9 December 2018. Submissions by letter, e-mail or fax cannot be considered.

- The following CME units can still be accessed for credit:

- "Arterial Hypertension" (issue 33-34/2018) until 11 November 2018,

- "Drug Hypersensitivity" (issue 29-30/2018) until 14 October 2018.

- This article has been certified by the North Rhine Academy for Continuing Medical Education. Participants in the CME program can manage their CME points with their 15-digit "uniform CME number" (einheitliche Fortbildungsnummer, EFN), which is found on the CME card (8027XXXXXXXXXXX). The EFN must be stated during registration on www.aerzteblatt.de ("Mein DÄ") or else entered in "Meine Daten," and the participant must agree to communication of the results. 


\section{CME credit for this unit can be obtained via cme.aerzteblatt.de until 9 December 2018.}

Only one answer is possible per question. Please choose the most appropriate answer

Question 1

What is the approximate 12-month prevalence of anxiety disorders among 14- to 65-year-olds in Europe?
a) $5 \%$
b) $14 \%$
c) $24 \%$
d) $34 \%$
e) $44 \%$

\section{Question 2}

What is the most common type of anxiety disorder?
a) Selective mutism
b) Panic disorder
c) Specific phobia
d) Social phobia
e) Generalized anxiety disorder

Question 3

What percentage of the development of anxiety disorders is accounted for by genetic factors?
a) $1-27 \%$
b) $30-67 \%$
c) $40-77 \%$
d) $50-87 \%$
e) $60-97 \%$

Question 6

Which of the following substances is effective against generalized anxiety disorder, according to clinical trials, but not approved for this purpose in Germany?
a) Lavender oil extract
b) Oil of St. John's wort
c) Ginger extract
d) Thyme extract
e) Sage extract

\section{Question 7}

What is a typical feature of a panic disorder?
a) Panic attacks arise exclusively in certain situations
b) Panic attacks begin unexpectedly.
c) The patient has a constant feeling of panic.
d) The patient complains of persistent worry.
e) Hypochondriac fears are expressed.

Question 8

What type of complementary treatment can be used beneficially in patients with anxiety disorders?
a) Bioresonance tomography
b) Aggression training
c) Hypnosis
d) Physical activity and exercise
e) Bach blossom therapy

\section{Question 4}

What type of psychotherapy is the treatment of first choice for anxiety disorders?
a) Psychoanalysis
b) Cognitive behavioral therapy
c) Psychodynamic psychotherapy
d) Talk psychotherapy
e) Eye movement desensitization and reprocessing (EMDR)

Question 9
How long after the end of the acute phase of successful drug treatment for panic disorder should the drug be continued for maintenance therapy?
a) 1 to 3 months
b) 3 to 6 months
c) 6 to 12 months
d) 12 to 18 months
e) 18 to 24 months

Question 5

What psychoactive drug(s) is/are the first line of drug therapy for anxiety disorders?
a) Benzodiazepines
b) Selective serotonin (and norepinephrine) reuptake inhibitors
c) Lithium
d) Neuroleptic drugs
e) T tricyclic antidepressants

\section{Question 10}

What is a typical feature of selective mutism?
a) It is a disease of old age.
b) The patient has a marked fear of bodily contact.
c) Girls of pubertal age are often affected.
d) The patient cannot speak in certain situations.
e) The patient cannot make eye contact. 
Additional material to:

\title{
The Diagnosis and Treatment of Anxiety Disorders
}

\author{
by Andreas Ströhle, Jochen Gensichen, and Katharina Domschke
}

Dtsch Arztebl Int 2018; 115: 611-20. DOI: 10.3238/arztebl.2018.0611

\section{eReferences}

e1. Eisner MD, Blanc PD, Yelin EH, et al.: Influence of anxiety on health outcomes in COPD. Thorax 2010; 65: 229-34.

e2. Tully PJ, Cosh SM, Baumeister $\mathrm{H}$ : The anxious heart in whose mind? A systematic review and meta-regression of factors associated with anxiety disorder diagnosis, treatment and morbidity risk in coronary heart disease. J Psychosom Res 2014; 77: 439-48.

e3. Burton C, Campbell P, Jordan K, Strauss V, Mallen C: The association of anxiety and depression with future dementia diagnosis: a case-control study in primary care. Fam Pract 2013; 30: 25-30.

e4. Grigsby AB, Anderson RJ, Freedland KE, Clouse RE, Lustman PJ: Prevalence of anxiety in adults with diabetes: a systematic review. J Psychosom Res 2002; 53: 1053-60.

e5. Beesdo K, Pine DS, Lieb R, Wittchen HU: Incidence and risk patterns of anxiety and depressive disorders and categorization of generalized anxiety disorder. Arch Gen Psychiatry 2010; 67: 47-57.

e6. American Psychiatric Association: Diagnostic and statistical manual of mental disorders. $5^{\text {th }}$ edition. DSM-5 2013.

e7. Shear KM, Bjelland I, Beesdo K, Gloster AT, Wittchen HU: Supplementary dimensional assessment in anxiety disorders. Int J Methods Psychiatr Res 2007; 16(Suppl 1): 52-64.

e8. Seligman ME: Phobias and preparedness-republished article. Behav Ther 2016; 47: 577-84.

e9. Naragon-Gainey K, Watson D: What lies beyond neuroticism? An examination of the unique contributions of social-cognitive vulnerabilities to internalizing disorders. Assessment 2018; 25: 143-58.

e10. Maneeton N, Maneeton B, Woottiluk P, et al.: Quetiapine monotherapy in acute treatment of generalized anxiety disorder: a systematic review and meta-analysis of randomized controlled trials. Drug Des Devel Ther 2016; 10: 259-76.

e11. Buoli M, Grassi S, Serati M, Altamura AC: Agomelatine for the treatment of generalized anxiety disorder. Expert Opin Pharmacother 2017; 18: 1373-9.

e12. Kasper S, Müller WE, Volz HP, Möller HJ, Koch E, Dienel A: Silexan in anxiety disorders: clinical data and pharmacological background. World J Biol Psychiatry 2017; 0: 1-9.

e13. Ströhle A, Feller C, Onken M, Godemann F, Heinz A, Dimeo F: The acute antipanic activity of aerobic exercise. Am J Psychiatry 2005; 162: 2376-8.

e14. Ströhle A, Graetz B, Scheel M, et al.: The acute antipanic and anxiolytic activity of aerobic exercise in patients with panic disorder and healthy control subjects. J Psychiatr Res 2009; 43: 1013-7.

e15. Lindenberger BL, Plag J, Schumacher S, et al.: Clinical and neurobiological effects of aerobic exercise in dental phobia: a randomized controlled trial. Depress Anxiety 2017; 34: 1040-8.

e16. Rapee RM, Kennedy SJ, Ingram M, Edwards SL, Sweeney L: Altering the trajectory of anxiety in at-risk young children. Am J Psychiatry 2010; 167: 1518-25.

e17. Rapee RM: The preventative effects of a brief, early intervention for preschool-aged children at risk for internalising: follow-up into middle adolescence. J Child Psychol Psychiatry 2013; 54: 780-8.

e18. Fisak BJ, Richard D, Mann A: The prevention of child and adolescent anxiety: a meta-analytic review. Prev Sci 2011; 12, 255-68.

e19. Moreno-Peral P, Conejo-Cerón S, Rubio-Valera M, et al.:

Effectiveness of psychological and/or educational interventions in the prevention of anxiety: a systematic review, meta-analysis, and meta-regression. JAMA Psychiatry 2017; 74, 1021-9. 